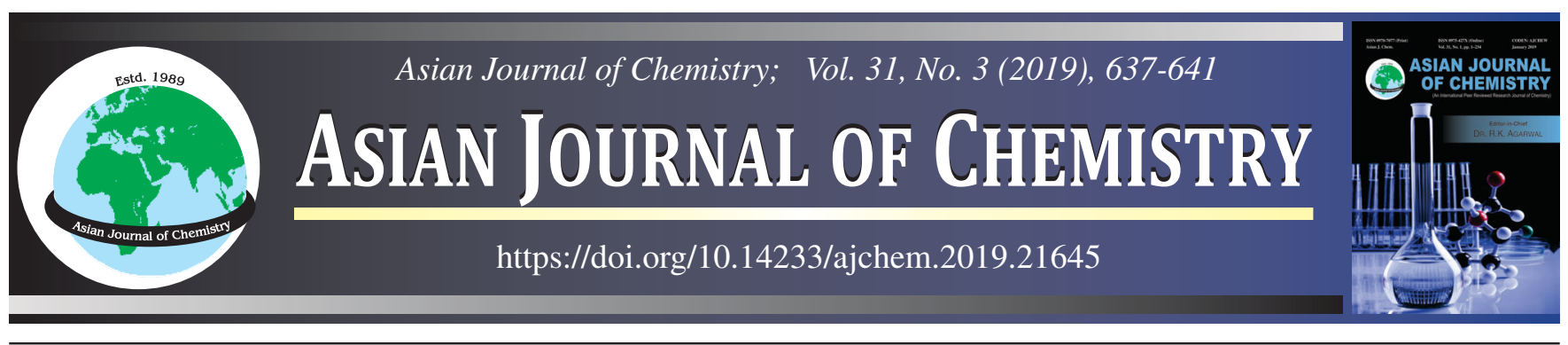

\title{
Synthesis of Cationic Pd(II) Complexes with 5-Membered Ring Chelating Iminoylcarbene Ligand and Its Catalytic Activity on Norbornene Polymerization
}

\author{
Roushown Ali, Jubaraj Chandra and Tariqul Hasan**
}

Department of Chemistry, Faculty of Science, University of Rajshahi, Rajshahi-6205, Bangladesh

*Corresponding author: Fax: +880 721 750064; E-mail: thasan.chem@ru.ac.bd

Received: 13 August 2018;

Accepted: 22 November 2018;

Published online: 31 January 2019;

AJC-19260

Iminoyl N-heterocyclic carbine ligand with cationic allyl Pd(II) complex (3) was successfully synthesized by transmetallation of corresponding Ag complex with one equivalent of $[\mathrm{Pd}(\mathrm{allyl})(\mathrm{COD})]^{+} \mathrm{SbF}_{6}^{-}$. A slightly distorted square planer structure of the $\mathrm{Pd}(\mathrm{II})$ complex $\mathbf{3}$ was confirmed by single crystal X-ray diffraction analysis. The Pd(II) complex $\mathbf{3}$ is stable in air and found to show moderate activity in the polymerization of norbornene without any activator. The polynorbornene produced with Pd(II) complex $\mathbf{3}$ was obtained to be stable up to $440{ }^{\circ} \mathrm{C}$. The ${ }^{1} \mathrm{H}$ and ${ }^{13} \mathrm{C}$ NMR spectra of the polymer indicated addition polymerization of norbornene and the presence of the vinylene group at the end of polymer chain.

Keywords: Cationicallyl Pd(II) complex, Iminoyl N-heterocyclic, Norbornene polymerization, Catalytic activity.

ᄂ - - - - - - - - - - - - - - - - - - - - - - - - - - - -

\section{INTRODUCTION}

$\mathrm{N}-$ Heterocyclic carbenes (NHCs) and their metal complexes have been the subject of significant research interests [1-8] because of their use as active catalyst or catalyst precursors for chemical transformation in the field of organometallics. The NHC leads to organometallic complexes those are often thermodynamically robust and act as active ligands [2-5]. Almost all the transition metals have the ability to coordinate with the NHC ligand [9]. Recently NHCs-derived transitionmetal complexes are being used widely for many reactions, such as olefin metathesis [10], hydrosilylation [11], C-C crosscoupling reactions [12], cycloaddition reactions [13], $\mathrm{CO} /$ ethylene copolymerization [14], atom transfer radical polymerization [15], but report of NHCs-derived metal complexes and their applications on olefin polymerizations is still limited [16-18].

Late-transition-metals have been developed [19-23] as catalysts for olefin polymerization. NHC-Ru complexes have been studied widely as their application in olefin metathesis catalysis [24-26] and have also been used in metathesis polymerization of different type of olefins [27,28]. However, research on the application of NHC ligands in addition polymerization of vinyl monomers is still limited. Nickel and palladium alkyls stabilized by NHC ligands undergo facile reductive elimination reactions leading to imidazolium salts, a process that may limit the applicability of such complexes to polymerization reactions [29].

It has been reported a widespread use of bidentate or polydentate ligands having strong and weak donor groups in homogeneous catalysis [30,31]. Recently there have been a few reports of metal complexes containing bidentate or polydentate carbene ligands and their use as catalyst precursors: such as $\mathrm{Pd}$ (pyimypy $)_{2}\left(\mathrm{PF}_{6}\right)_{2}$ for copolymerization of $\mathrm{CO} /$ norbornene [32], bis(carbine)pyridine complexes of $\mathrm{Ti}$ and $\mathrm{V}$ for the polymerization of ethylene [33], picolyl-functionalized NHC carbine Ni complex for the homopolymerization of norbornene and ethylene [34], NHC carbene enolate Ni(II) complex for the polymerization of ethylene [35], tridentate salicylaldiminato NHC Ni complex for the polymerization of styrene [36]. Cationic allyl nickel complexes stabilized by a single N-heterocyclic carbene ligand and a labile aquo or acetonitrile ligand for the polymerization of 1,3-butadiene and styrene [37]. Goodall et. al. [38] patented the results of the polymerization of functional norbornene with monodented NHC palladium allyl complexes. Chung et. al. [39] reported the polymerization of functional norbornene with similar NHC palladium allyl complexes. Bis(aryloxide-N-heterocyclic carbene) palladium and aryl-

This is an open access journal, and articles are distributed under the terms of the Creative Commons Attribution-NonCommercial-ShareAlike 4.0 (CC BY-NC-SA 4.0) International License which allows readers to freely read, download, copy, distribute, print, search, or link to the full texts of its articles and to use them for any other lawful non-commercial purpose as long as the original source is duly acknowledged. 
oxide-N-heterocyclic carbene ligated palladacycles have been reported for the homopolymerization of norbornene [40,41]. Juean et al. [42] reported imine-N-heterocyclic carbene palladium complexes for the homopolymerization of norbornene. The properties of the NHC ligands have been growing importance of metal complexes for olefin polymerization catalysts.

In this paper, we have synthesized and characterized a bidentate iminoyl NHC carbene ligand containing cationic allyl Pd(II) complex. Here, at first a cationic five-membered palladium complex was synthesized that exhibited good stability. Thereafter, bidentate iminoyl NHC carbene palladium complex was used as catalyst precursors for norbornene polymerization. Single crystal X-ray diffraction analysis and NMR spectra were used to characterize the structure of $\mathrm{Pd}$ (II) complex 3 and polynorbornene, respectively.

\section{EXPERIMENTAL}

All reactions involving organometallic compounds were carried out using the Schlenk technique unless otherwise noted. Solvents for synthesis of complex and polymerization reaction were dried according to standard procedures. Commercial grade 2,6-diisopropylaniline, benzoyl chloride, 1-methylimidazole, silver oxide, silver hexafloroantimonate, allyl palladium chloride were purchased from Aldrich. $[\mathrm{Pd}(\text { allyl })(\mathrm{COD})]^{+} \mathrm{SbF}_{6}{ }^{-}$was synthesized according to the reference $[42,43]$. Norbornene was purified by stirring it over calcium hydride at $60{ }^{\circ} \mathrm{C}$ for $24 \mathrm{~h}$ and then distilled. A standard solution of norbornene in toluene $(1 \mathrm{M})$ was prepared and stored in a Schlenk tube.

Polymerization procedure: Polymerizations were carried out in a $100 \mathrm{~mL}$ glass reactor equipped with a sealed septum and a magnetic stirrer under a nitrogen atmosphere. The reactor was charged with a prescribed amount of the norbornene solution in toluene with a syringe. Solvent was added to make the total volume $30 \mathrm{~mL}$. The reactor was kept in a water or oil bath at required temperature. A solution of Pd-complex (20 $\mu \mathrm{mol})$ in methylene chloride $(1 \mathrm{~mL})$ and toluene $(1 \mathrm{~mL})$ was added to start the polymerization. The polymerization was terminated after certain time with methanol and precipitated in acidic methanol with stirring overnight. The polymers obtained were filtered, adequately washed with methanol and dried under vacuum at $60^{\circ} \mathrm{C}$ for $6 \mathrm{~h}$.

Analytical procedures: Molecular weight $\left(\mathrm{M}_{\mathrm{n}}\right)$ and molecular weight distribution $\left(M_{w} / M_{n}\right)$ of polymer were measured by GPC (Waters $150 \mathrm{C}$ ) at $140{ }^{\circ} \mathrm{C}$ using $o$-dichlorobenzene as solvent and calibrated by polystyrene standards. ${ }^{1} \mathrm{H}$ NMR and ${ }^{13} \mathrm{C}$ NMR spectra of the copolymers were recorded at $120{ }^{\circ} \mathrm{C}$ on a JEOL GX 500 spectrometer operated at $125.65 \mathrm{MHz}$ in pulse Fourier Transform mode with tetrachloroethane- $d_{2}$ as solvent. The peak of tetrachloroethane in tetrachloroethane$d_{2}$ (5.90 ppm for ${ }^{1} \mathrm{H}$ NMR and $74.47 \mathrm{ppm}$ for ${ }^{13} \mathrm{C}$ NMR) was used as internal reference. Thermal gravimetric analysis (TGA) was studied with Seiko I \& EDTA-220 under a nitrogen atmosphere up to $600{ }^{\circ} \mathrm{C}$ at heating rate of $10^{\circ} \mathrm{C} / \mathrm{min}$. Differential Scanning Calorimetric (DSC) analysis was done on a Seiko DSC-220 under a nitrogen atmosphere from 20 to $400{ }^{\circ} \mathrm{C}$ on heating and cooling rate of $10^{\circ} \mathrm{C} / \mathrm{min}$.

Synthesis of cationic Pd(II) complex (3): The Pd(II) complex $\mathbf{3}$ was synthesized according to Scheme-I. The ligand (1) and the silver iminoylcarbene complex (2) were prepared according to the reference [44]. The cationic Pd(II) complex $\mathbf{3}$ was obtained by transmetalation of the Ag carbine $\mathbf{2}$ with $[\mathrm{Pd}(\text { allyl })(\mathrm{COD})]^{+} \mathrm{SbF}_{6}^{-}$.

In a $100 \mathrm{~mL}$ Schlenk tube $[\mathrm{Pd}(\text { allyl })(\mathrm{COD})]^{+} \mathrm{SbF}_{6}^{-}(138 \mathrm{mg}$, $0.282 \mathrm{mmol}$ ) and $5 \mathrm{~mL} \mathrm{CH}_{2} \mathrm{Cl}_{2}$ were charged under nitrogen. The tube was kept at $-30{ }^{\circ} \mathrm{C}$ and a solution of $\mathrm{Ag}$ carbine 2 (140 mg, $0.282 \mathrm{mmol}$ ) in $4 \mathrm{~mL} \mathrm{CH} \mathrm{Cl}_{2}$ was added. The mixture was stirred for $6 \mathrm{~h}$ at room temperature. The precipitate formed was filtered through celite and the filtrate was dried under vacuum. The white solid obtained was dissolved in $\mathrm{CH}_{2} \mathrm{Cl}_{2}$ and triturated with hexane. The mixture was kept at room temperature overnight to afford prismatic white crystal. Finally, the crystal was filtered and dried under vacuum $(166 \mathrm{mg}, 82 \%)$. ${ }^{1} \mathrm{H}$ NMR $\left(125 \mathrm{MHz}, \mathrm{CDCl}_{3}\right): \delta 0.95\left(\mathrm{dd}, 6 \mathrm{H},-\mathrm{CH}-\left(\mathrm{CH}_{3}\right)_{2}\right)$, $1.10\left(\mathrm{~d}, 3 \mathrm{H},-\mathrm{CH}-\mathrm{CH}_{3}\right), 1.21$ (d, 3H, -CH-CH $\left.{ }_{3}\right), 2.94$ (sept, $1 \mathrm{H}$, - $\left.\mathrm{CH}-\left(\mathrm{CH}_{3}\right)_{2}\right), 3.01$ (d, $1 \mathrm{H}$, allyl), 3.12 (sept, $\left.1 \mathrm{H},-\mathrm{CH}-\left(\mathrm{CH}_{3}\right)_{2}\right)$, $3.31\left(\mathrm{~d}, 1 \mathrm{H}\right.$, allyl), 3.54 (d, 1H, allyl), 3.97 (s, $\left.3 \mathrm{H}, \mathrm{N}-\mathrm{CH}_{3}\right)$, $4.18(\mathrm{~d}, 1 \mathrm{H}$, allyl), $5.51(\mathrm{~m}, 1 \mathrm{H}$, central allyl), $7.06(\mathrm{~m}, 3 \mathrm{H}$, $A r$-di $\mathrm{P} P$ ), 7.16 (d, 1H, NCHCHN, near to $\left.\mathrm{N}-\mathrm{CH}_{3}\right), 7.31-7.40$ $(\mathrm{m}, 5 \mathrm{H}, P h), 7.49\left(\mathrm{~d}, 1 \mathrm{H}, \mathrm{NCHCHN}\right.$, near to imine). ${ }^{13} \mathrm{C}$ NMR $\left(125 \mathrm{MHz}, \mathrm{CDCl}_{3}\right): \delta 20.1,20.4,21.5,21.8,25.8,26.0,37.1$, 47.1, 73.8, 117.5, 117.7, 121.6, 121.8, 122.7, 125.2, 126.6, 130.3, 136.5, 140.1, 159.4, 179.9 .

\section{RESULTS AND DISCUSSION}

The cationic Pd(II) complex 3 was prepared from the transmetallation of Ag complex 2 with one equivalent of $[\mathrm{Pd}(\text { allyl })(\mathrm{COD})]^{+} \mathrm{SbF}_{6}^{-}$. The product was obtained in high yield $(82 \%)$ and was stable in air. Colourless prismatic crystal of Pd(II) complex $\mathbf{3}$ was suitable for single crystal X-ray diffraction analysis. An ORTEP drawing of the molecular structure of complex $\mathbf{3}$ was displayed in Fig. 1. The structure verifies that the complex contains $\mathrm{C} / \mathrm{N}$ chelating imino carbene ligand. Selected bond lengths and bond angles of complex $\mathbf{3}$ are given in Table-1. The central carbon of allyl was found to be disordered, where population was assumed to be 0.5 at each position. The allyl carbon trans to carbine shows significant length $(9.5$

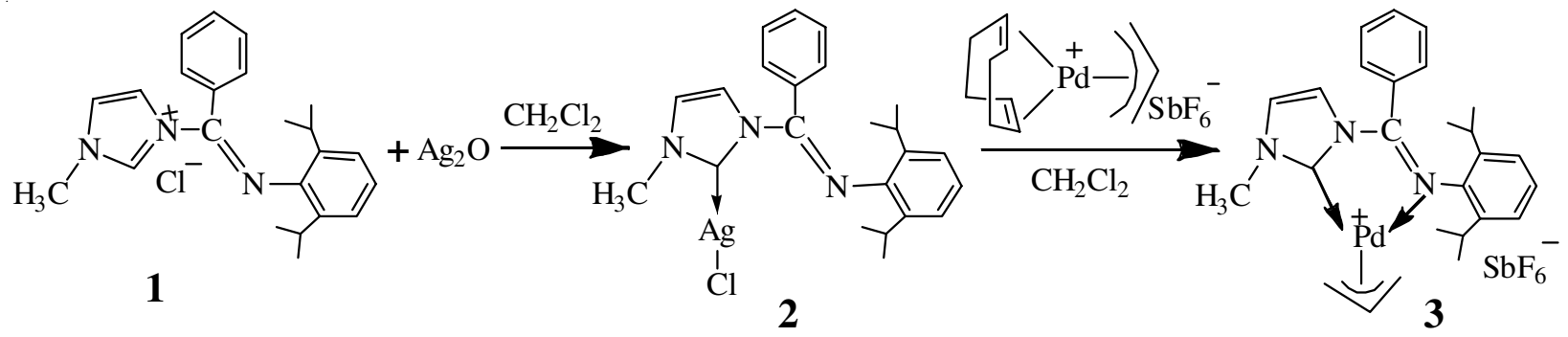

Scheme-I: Synthesis of cationic $\mathrm{Pd}(\mathrm{II})$ complex by transmetalation of $\mathrm{Ag}$ carbene with $[\mathrm{Pd}(\mathrm{allyl})(\mathrm{COD})]^{+} \mathrm{SbF}_{6}$ 

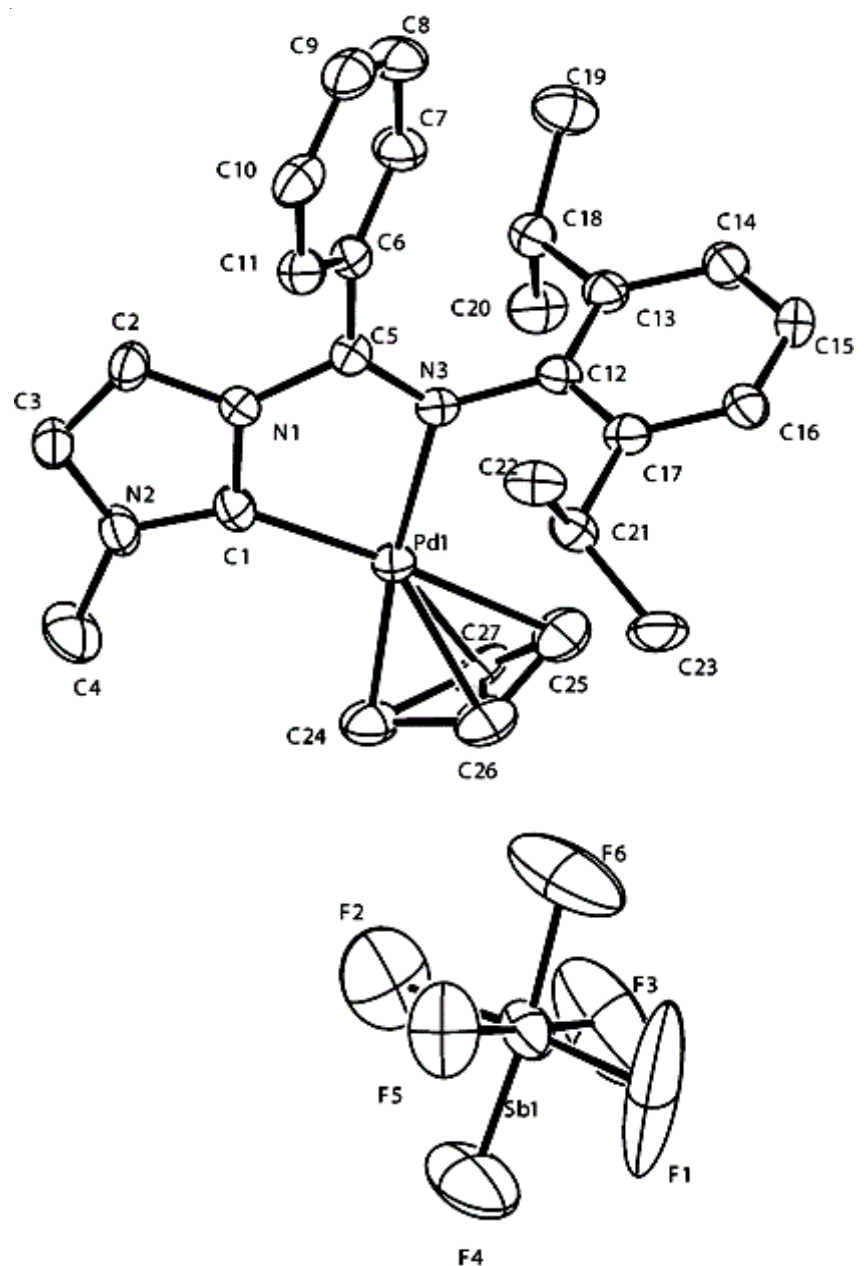

Fig. 1. ORTEP plot of Pd(II) complex (3). Hydrogen atoms are omitted for clarity

TABLE-1

SELECTIVE BOND LENGTHS AND

BOND ANGLES OF Pd(II)-COMPLEX 3

\begin{tabular}{ll|ll}
\hline \multicolumn{1}{c|}{ Bond lengths } & \multicolumn{1}{c}{$\AA$} & \multicolumn{1}{c}{ Bond angle } & \multicolumn{1}{c}{${ }^{\circ}$} \\
\hline $\operatorname{Pd}(1)-\mathrm{N}(3)$ & $2.136(2)$ & $\mathrm{Pd}(1)-\mathrm{C}(1)-\mathrm{N}(1)$ & $113.05(12)$ \\
$\operatorname{Pd}(1)-\mathrm{C}(1)$ & $2.0125(19)$ & $\mathrm{Pd}(1)-\mathrm{C}(1)-\mathrm{N}(2)$ & $142.89(15)$ \\
$\mathrm{N}(1)-\mathrm{C}(1)$ & $1.382(2)$ & $\mathrm{N}(3)-\mathrm{Pd}(1)-\mathrm{C}(1)$ & $78.42(7)$ \\
$\mathrm{N}(2)-\mathrm{C}(1)$ & $1.348(2)$ & $\mathrm{C}(1)-\mathrm{Pd}(1)-\mathrm{C}(24)$ & $107.16(8)$ \\
$\operatorname{Pd}(1)-\mathrm{C}(24)$ & $2.100(2)$ & $\mathrm{N}(3)-\mathrm{Pd}(1)-\mathrm{C}(25)$ & $105.44(10)$ \\
$\operatorname{Pd}(1)-\mathrm{C}(25)$ & $2.195(3)$ & & \\
$\operatorname{Pd}(1)-\mathrm{C}(26)$ & $2.185(7)$ & & \\
$\operatorname{Pd}(1)-\mathrm{C}(27)$ & $2.136(4)$ & & \\
\hline
\end{tabular}

ppm) relative to the allyl carbon trans to the imine. The most striking feature of the structure is that the square plane of the $\mathrm{Pd}$, the imidazole ring and the 5-membered chelate ring are all coplanar. A significant ring strain on the chelate is evidenced by the fact that the two N(imidazole)-C(carbine)-Pd angles differ by $29.8^{\circ}$ [Pd(1)-C(1)-N(2), 142.89(15)], [Pd(1)-C(1)N(1), 113.05(12)].

Polymerization of norbornene with complex 3: $\mathrm{Pd}(\mathrm{II})$ complex $\mathbf{3}$ as a single component was evaluated as catalyst for polymerization of norbornene at 50 and $80{ }^{\circ} \mathrm{C}$ in different reaction medium. The polymerization results listed in Table- 2 show that the Pd-complex $\mathbf{3}$ led to active catalyst. Temperature and solvent significantly affected the behaviour of the homopolymerization of norbornene. The activity of complex $\mathbf{3}$ was 2.75 times higher at $80{ }^{\circ} \mathrm{C}$ but the molecular weight of the polymer was about 4 times lower than the polymer obtained in same condition at $50{ }^{\circ} \mathrm{C}$ in toluene (entry 1 and 2 ). The catalytic activity was double and the molecular weight of the polymer obtained was increased three times, when the polymerization was carried out in a mixture of toluene and dichloromethane $(1: 1)$ at $50{ }^{\circ} \mathrm{C}$ (entry 1 and 3 ). At longer polymerization time $(8 \mathrm{~h})$, the yield was $84 \%$ and high molecular weight polynorbornene was obtained. This result indicated that the catalyst was stable for long time during polymerization. When $10 \mu \mathrm{mol}$ of catalyst $\mathbf{3}$ was applied, the activity was more than double compared with that of $20 \mu \mathrm{mol}$ and the molecular weight also increased (entry 4 and 5). The narrow molecular weight distribution of all the polymers obtained $\left(\mathrm{M}_{\mathrm{w}} / \mathrm{M}_{\mathrm{n}}=1.48\right.$ to 2.17$)$ indicated the single active species during polymerization.

Cationic palladium complexes [(3-Me-1-(2,6-diisopropylphenyl)iminyl- $\left.\left.\mathrm{C}_{3} \mathrm{H}_{2} \mathrm{~N}_{2}\right)-\mathrm{PdMeCH}_{3} \mathrm{CN}\right]^{+} \mathrm{BAF}^{-}$and [(3(2,4,6-trimethylphenyl)-1-(2,6-diisopropylphenyl)iminyl$\mathrm{C}_{3} \mathrm{H}_{2} \mathrm{~N}_{2}$ ) $\mathrm{PdMeCH}_{3} \mathrm{CN}^{+} \mathrm{BAF}^{-}$were also reported [42] as active for norbornene polymerization without cocatalysts. Thermal stability of the cationic palladium complexes for norbornene polymerization was also observed.

The polynorbornene obtained was soluble in NMR solvent $\left(\mathrm{C}_{2} \mathrm{D}_{2} \mathrm{Cl}_{4}\right)$. The ${ }^{1} \mathrm{H}$ and ${ }^{13} \mathrm{C}$ NMR analyses of polynorbornene were performed in solution. The ${ }^{1} \mathrm{H}$ NMR spectrum of polynorbornene is displayed in Fig. 2. A broad signal containing four main peaks are observed around 0.99-2.30 ppm, which are assigned to methylene $\left(\mathrm{CH}_{2}\right)$ protons at $0.99-1.48$ and methane $(\mathrm{CH})$ protons at $1.79-2.30 \mathrm{ppm}$. Three new signals were observed at unsaturated region: two broad singlets at 5.70 and $4.70 \mathrm{ppm}$ and a broad multiplet at $5.37 \mathrm{ppm}$. The relative intensities of these signals were about $1: 1: 1$.

The two downfield peaks at 5.70 and $5.37 \mathrm{ppm}$ are assignable to $\mathrm{N}-\mathrm{HC}=\mathrm{CH}-\mathrm{CH}_{3}$ proton and $\mathrm{N}-\mathrm{HC}=\mathrm{CH}-\mathrm{CH}_{3}$ proton, respectively, indicate the presence of vinylene group at the end of the polynorbornene chain. The origin of the peak at $4.70 \mathrm{ppm}$ is not clear at present.

TABLE-2

HOMOPOLYMERIZATION OF NORBORNENE WITH Pd(II) COMPLEX $3^{\text {a }}$

\begin{tabular}{ccccccc}
\hline Entry & Temperature $\left({ }^{\circ} \mathrm{C}\right)$ & Time $(\mathrm{h})$ & Yield $(\mathrm{g})$ & Activity $^{\mathrm{b}}$ & $\mathrm{M}_{\mathrm{n}} \times 10^{-3 \mathrm{c}}$ & $\mathrm{M}_{\mathrm{w}} / \mathrm{M}_{\mathrm{n}}^{\mathrm{c}}$ \\
\hline 1 & 50 & 4 & 0.34 & 4 & 2.3 & 5.17 \\
2 & 80 & 4 & 0.87 & 11 & 63.9 & 1.72 \\
$3^{\mathrm{d}}$ & 50 & 4 & 0.70 & 15 & 94.8 & 1.48 \\
$4^{\mathrm{d}}$ & 50 & 8 & 2.38 & 33 & 1.80 \\
$5^{\mathrm{e}}$ & 50 & 8 & 2.62 & 110.0 & 1.68 \\
\hline
\end{tabular}

${ }^{\mathrm{a}}$ Polymerization conditions; $\mathrm{Pd}=20 \mu \mathrm{mol}, \mathrm{N}=30 \mathrm{mmol}$, solvent $=$ toluene, total volume $=30 \mathrm{~mL},{ }^{\mathrm{b}} \mathrm{Activity}=\mathrm{kg}(\mathrm{poly}) \cdot \mathrm{mol}{ }^{-1}(\mathrm{Pd}) \cdot \mathrm{h}^{-1},{ }^{\mathrm{c}} \mathrm{Number}$ average molecular weight and molecular weight distribution were measured by GPC analysis using polystyrene standard. ${ }^{\mathrm{d}}$ Solvent $=($ toluene 15 $\mathrm{mL}+$ dichloromethane $15 \mathrm{~mL}$ ). ${ }^{\mathrm{e}} \mathrm{Pd}=10 \mu \mathrm{mol}$ and Solvent $=$ (toluene $15 \mathrm{~mL}+$ dichloromethane $15 \mathrm{~mL}$ ). 


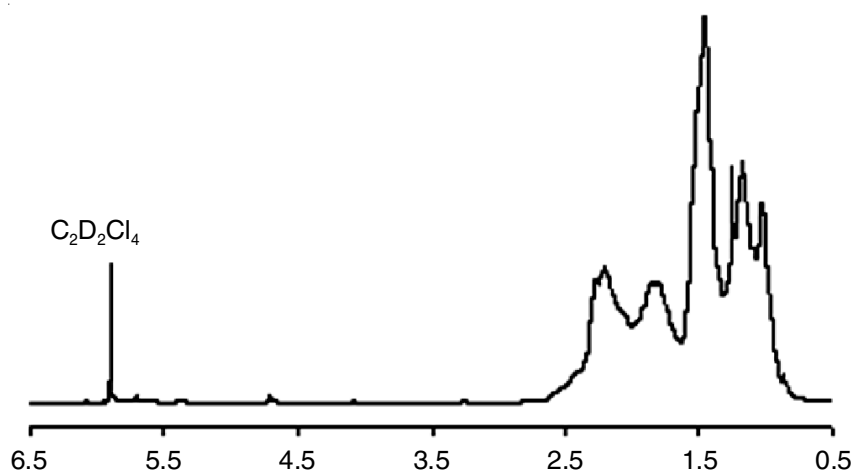

Fig. 2. ${ }^{1} \mathrm{H}$ NMR spectrum of polynorbornene obtained with 3 (entry 1)

In ${ }^{13} \mathrm{C}$ NMR spectrum of the polynorbornene (Fig. 3), the signals assignable to saturated carbons are appeared at 28 to $55 \mathrm{ppm}$ as observed in the spectrum of the polynorbornene obtained from vinyl addition process $[45,46]$ and five new peaks were observed at unsaturated region from 120.91 to $129.54 \mathrm{ppm}$ correspond to cis-trans isomer of vinylene $-\mathrm{CH}=\mathrm{CH}-\mathrm{CH}_{3}$ end group. No peak was observed at about 114 ppm or 136-138 ppm in the ${ }^{13} \mathrm{C}$ NMR spectrum that indicated the absence of vinyl $\left(-\mathrm{CH}=\mathrm{CH}_{2}\right)$ end group in the polymer chain. The results suggested that the vinylene group was form by the isomerization of allyl group after the polymerization.

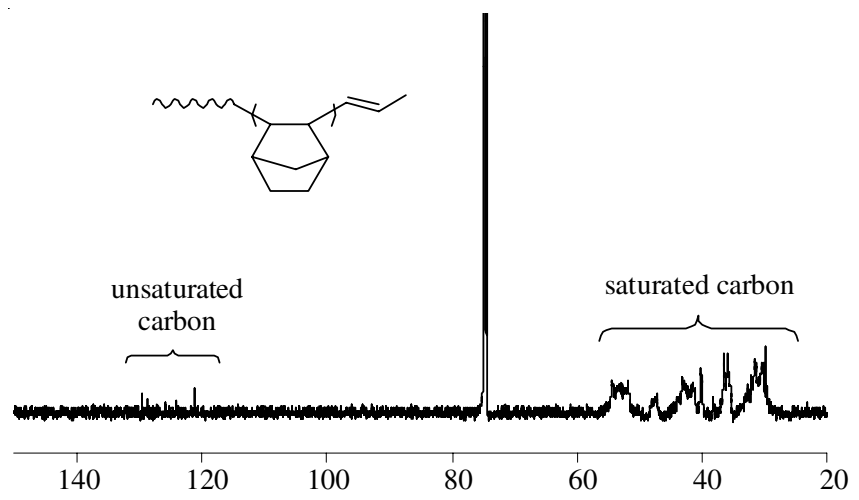

Fig. 3. ${ }^{13} \mathrm{C}$ NMR spectrum of polynorbornene obtained with $\mathrm{Pd}(\mathrm{II})$ complex 3 (entry 1)

The saturated region of the ${ }^{13} \mathrm{C}$ NMR spectrum from 25 to $65 \mathrm{ppm}$ was expanded and displayed in Fig. 4. The signals of saturated carbons of polynorborne chain were observed in the range of 29.7-54.5 ppm. Each signal of saturated carbon was split into several peaks, which might come from different stereoisomers of norbornene unit in the polymer chain. The peaks were assigned as four groups by comparing peaks areas as follows: C5/C6 (29.5-33.5 ppm), C7 (35.5-38.5 ppm), C1/ C2 (38.5-45 ppm and C2/C3 (47.4-54.5 ppm). Although the clear assignment of each peak was not accomplished, the three peaks of C7 carbon clearly appeared at 36.00, 36.64 and 38.29 ppm. Two peaks at 36.00 and 36.64 ppm were almost equal intensity, which suggest that the polynorbornene obtained is atactic.

The thermal property of the polynorbornene obtained from entry 5 was studied by thermogravimetric analysis. A weight loss of $4 \%$ was recorded at $322{ }^{\circ} \mathrm{C}$ and the polynorbornene was completely decomposed at $446{ }^{\circ} \mathrm{C}$.

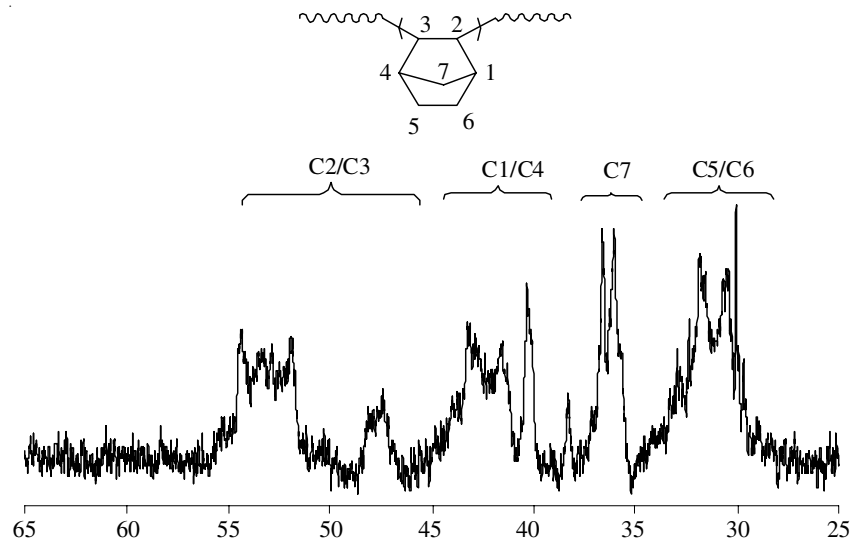

Fig. 4. ${ }^{13} \mathrm{C}$ NMR spectrum (25-65 ppm) of polynorbornene obtained with 3 (entry 1)

\section{Conclusion}

A cationic allyl Pd(II) complex 3 with $\mathrm{N}$-heterocyclic carbene ligand was synthesized from the transmetallation of corresponding Ag complex with one equivalent of [Pd(allyl)$(\mathrm{COD})]^{+} \mathrm{SbF}_{6}^{-}$. The product was obtained in high yield $(82 \%)$ and was stable in air. The cationic palladium complex was also observed to be thermally stable as catalyst and increase the activity for long time polymerization. The molecular structure of the complex was confirmed by X-ray single crystal analysis. The NMR spectra proved the polymerization of norbornene with cationic palladium complex. The $\mathrm{Pd}(\mathrm{II})$ complex was found moderate activity for the addition polymerization of norbornene without any activator. The polynorbornene was found to be stable up to $440{ }^{\circ} \mathrm{C}$. In polynorbornene structure, the vinylene group was obtained at the end of polymer chain.

\section{ACKNOWLEDGEMENTS}

The authors are grateful to Department of Applied Chemistry, Hiroshima University, Japan for providing instrumental facilities for carrying out X-ray diffraction experiment, recording NMR spectra and measuring GPC of the polymer samples.

\section{CONFLICT OF INTEREST}

The authors declare that there is no conflict of interests regarding the publication of this article.

\section{REFERENCES}

1. A.J. Arduengo, R.L. Harlow and M. Kline, J. Am. Chem. Soc., 113, 361 (1991);

https://doi.org/10.1021/ja00001a054.

2. F. Glorius, N-Heterocyclic Carbenes in Transition Metal Catalysis, Springer: Berlin, Heidelberg (2007).

3. M.N. Hopkinson, C. Richter, M. Schedler and F. Glorius, Nature, 510, 485 (2014); https://doi.org/10.1038/nature13384.

4. T. Weskamp, V.P.W. Böhm and W.A. Herrmann, J. Organomet. Chem., 600, 12 (2000); https://doi.org/10.1016/S0022-328X(00)00035-8.

5. N.M. Scott and S.P. Nolan, Eur. J. Inorg. Chem., 2005, 1815 (2005); https://doi.org/10.1002/ejic.200500030.

6. E. Peris and R.H. Crabtree, Coord. Chem. Rev., 248, 2239 (2004); https://doi.org/10.1016/j.ccr.2004.04.014.

7. W.A. Herrmann, Angew. Chem. Int. Ed., 41, 1290 (2002); https://doi.org/10.1002/1521-3773(20020415)41:8<1290::AIDANIE1290>3.0.CO;2-Y 
8. A.J. Arduengo Jr., Acc. Chem. Res., 32, 913 (1999); https://doi.org/10.1021/ar980126p.

9. S. Díez-González, N. Marion and S.P. Nolan, Chem. Rev., 109, 3612 (2009); https://doi.org/10.1021/cr900074m.

10. T.M. Trnka and R.H. Grubbs, Acc. Chem. Res., 34, 18 (2001); https://doi.org/10.1021/ar000114f.

11. H.M. Lee, D.C. Smith, Z.J. He, E.D. Stevens, C.S. Yi and S.P. Nolan, Organometallics, 20, 794 (2001); https://doi.org/10.1021/om000882a.

12. L. Yin and L. Liebscher, Chem. Rev., 107, 133 (2007); https://doi.org/10.1021/cr0505674.

13. G.C. Fortman and S.P. Nolan, Chem. Soc. Rev., 40, 5151 (2011); https://doi.org/10.1039/c1cs15088j.

14. M.G. Gardiner, W.A. Herrmann, C.P. Reisinger, J. Schwarz and M. Spiegler, J. Organomet. Chem., 572, 239 (1999); https://doi.org/10.1016/S0022-328X(98)00960-7.

15. X. Sauvage, Y. Borguet, A.F. Noels, L. Delaude and A. Demonceau, Adv. Synth. Catal., 349, 255 (2007); https://doi.org/10.1002/adsc.200600515.

16. V. Khlebnikov, A. Meduri, H. Mueller-Bunz, T. Montini, P. Fornasiero, E. Zangrando, B. Milani and M. Albrecht, Organometallics, 31, 976 (2012); https://doi.org/10.1021/om201027y.

17. V. Khlebnikov, A. Meduri, H. Mueller-Bunz, B. Milani and M. Albrecht, New J. Chem., 36, 1552 (2012); https://doi.org/10.1039/c2nj40287d.

18. D. McGuinness, Dalton Trans., 6915 (2009); https://doi.org/10.1039/b906479f.

19. S. Mecking, Angew. Chem. Int. Ed., 40, 534 (2001); https://doi.org/10.1002/1521-3773(20010202)40:3<534::AIDANIE534>3.0.CO;2-C.

20. S. Ito, K. Munakata, A. Nakamura and K. Nozaki, J. Am. Chem. Soc., 131, 14606 (2009); https://doi.org/10.1021/ja9050839.

21. S.D. Ittel, L.K. Johnson and M. Brookhart, Chem. Rev., 100, 1169 (2000); https://doi.org/10.1021/cr9804644.

22. H. Gao, H. Hu, F. Zhu and Q. Wu, Chem. Commun., 48, 3312 (2012); https://doi.org/10.1039/c2cc17154f.

23. S. Zai, H. Gao, Z. Huang, H. Hu, H. Wu and Q. Wu, ACS Catal., 2, 433 (2012); https://doi.org/10.1021/cs200593c.

24. S.P. Nolan, N-Heterocyclic Carbenes in Synthesis, Wiley-VCH: Weinheim, Germany (2006).

25. S.T. Nguyen and T.M. Trnka, ed.: R.H. Grubbs, Handbook of Metathesis, Wiley-VCH: Weinheim, Germany, vol. 1 (2003).

26. B.F. Straub, Angew. Chem. Int. Ed., 44, 5974 (2005); https://doi.org/10.1002/anie.200501114.

27. M.R. Buchmeiser, Chem. Rev., 100, 1565 (2000); https://doi.org/10.1021/cr990248a.

28. C.W. Bielawski and R.H. Grubbs, Angew. Chem. Int. Ed., 39, 2903 (2000);

https://doi.org/10.1002/1521-3773(20000818)39:16<2903::AIDANIE2903>3.0.CO:2-Q.
29. N.D. Clement and K.J. Cavell, Angew. Chem. Int. Ed., 43, 3845 (2004); https://doi.org/10.1002/anie.200454166.

30. W. Keim, Angew. Chem. Int. Ed. Engl., 29, 235 (1990); https://doi.org/10.1002/anie.199002351.

31. E. Drent, P. Arnoldy and P.H.M. Budzelaar, J. Organomet. Chem., 475, 57 (1994); https://doi.org/10.1016/0022-328X(94)84007-5.

32. J.C.C. Chen and I.J.B. Lin, Organometallics, 19, 5113 (2000); https://doi.org/10.1021/om000557n.

33. D.S. McGuinness, V.C. Gibson and J.W. Steed, Organometallics, 23, 6288 (2004); https://doi.org/10.1021/om049246t.

34. X. Wang, S. Liu and G.-X. Jin, Organometallics, 23, 6002 (2004); https://doi.org/10.1021/om049467z.

35. B.E. Ketz, X.G. Ottenwaelder and R.M. Waymouth, Chem. Commun., 5693 (2005); https://doi.org/10.1039/b511202h

36. W. Li, H. Sun, M. Chen, Z. Wang, D. Hu, Q. Shen and Y. Zhang, Organometallics, 24, 5925 (2005); https://doi.org/10.1021/om050612y.

37. J. Cámpora, L. Ortiz de la Tabla, P. Palma, E. Álvarez, F. Lahoz and K. Mereiter, Organometallics, 25, 3314 (2006); https://doi.org/10.1021/om0604391.

38. B.L. Goodall, T.C. Kirk and L.H. McIntosh III, Preparation of Linear Ethylene-Acrylate Copolymers with Palladium Catalysts and Free Radical Scavengers, US Patent 7524912B2 (2009).

39. I.G. Jung, J.H. Seo, Y.K. Chung, D.M. Shin, S.-H. Chun and S.U. Son, J. Polym. Sci. A Polym. Chem., 45, 3042 (2007); https://doi.org/10.1002/pola.22060.

40. Y. Kong, L. Wen, H. Song, S. Xu, M. Yang, B. Liu and B. Wang, Organometallics, 30, 153 (2011); https://doi.org/10.1021/om100994s.

41. Y. Kong, H. Ren, S. Xu, H. Song, B. Liu and B. Wang, Organometallics, 28, 5934 (2009); https://doi.org/10.1021/om900625r.

42. J. Deng, H. Gao, F. Zhu and Q. Wu, Organometallics, 32, 4507 (2013); https://doi.org/10.1021/om400268y.

43. D.A. White, J.R. Doyle and H. Lewis, Inorg. Synth., 13, 55 (1972).

44. M. Frøseth, K.A. Netland, C. Rømming and M. Tilset, J. Organomet. Chem., 690, 6125 (2005); https://doi.org/10.1016/j.jorganchem.2005.08.008.

45. T. Hasan, K. Nishii, T. Shiono and T. Ikeda, Macromolecules, 35, 8933 (2002); https://doi.org/10.1021/ma025586j.

46. D.A. Barnes, G.M. Benedikt, B.L. Goodall, S.S. Huang, H.A. Kalamarides, S. Lenhard, L.H. McIntosh, K.T. Selvy, R.A. Shick and L.F. Rhodes, Macromolecules, 36, 2623 (2003); https://doi.org/10.1021/ma030001m. 